Article

\title{
The Cyberdivisions Produced by the Design of VGI under the Platform Economy: The Case of the Restaurant Sector in TripAdvisor
}

\author{
Daniela Ferreira $^{1, * \mathbb{C}}$, Mário Vale ${ }^{2}$ and Renato Miguel Carmo ${ }^{3}$ \\ 1 Centre of Geographical Studies, Institute of Geography and Spatial Planning, Universidade de Lisboa, \\ 1600-276 Lisbon, Portugal \\ 2 Centre of Geographical Studies, Laboratório Associado TERRA, Institute of Geography and Spatial Planning, \\ Universidade de Lisboa, 1600-276 Lisbon, Portugal; mario.vale@campus.ul.pt \\ 3 Centre for Research and Studies in Sociology (CIES-Iscte), ISCTE-University Institute of Lisbon, \\ 1649-026 Lisbon, Portugal; renato.carmo@iscte.pt \\ * Correspondence: danielaferreira2@campus.ul.pt
}

Citation: Ferreira, D.; Vale, M.; Carmo, R.M. The Cyberdivisions Produced by the Design of VGI under the Platform Economy: The Case of the Restaurant Sector in TripAdvisor. ISPRS Int. J. Geo-Inf. 2021, 10, 717. https://doi.org/10.3390/ijgi10110717

Academic Editors: Guiming Zhang, A-Xing Zhu and Wolfgang Kainz

Received: 31 August 2021

Accepted: 18 October 2021

Published: 22 October 202

Publisher's Note: MDPI stays neutral with regard to jurisdictional claims in published maps and institutional affiliations.

Copyright: (c) 2021 by the authors. Licensee MDPI, Basel, Switzerland. This article is an open access article distributed under the terms and conditions of the Creative Commons Attribution (CC BY) license (https:// creativecommons.org/licenses/by/ $4.0 /)$.
Abstract: There is increasing concern regarding the inequalities produced by digital platforms based on volunteered geographic information (VGI). Several forms of inequalities have been observed namely the unequal spatial coverage and the uneven levels of usage even in territories with good coverage. However, VGI platforms under the logic of platform economy have generated other forms of spatial inequality that require more attention. The cyberspace within VGI platforms is producing different cyberspatialities, especially with the platformisation processes that have made this type of inequality more evident. With this in mind, this paper aims to explore the making of cyberdivisions under the platform economy. We argue that the design of VGI within digital platforms is generating cyberdivisions in the urban economy. This research is particularly interested in exploring the restaurant sector in the TripAdvisor platform in the city of Lisbon. In this paper, we draw on a representative survey by questionnaire to restaurant firm owners. We obtained 385 responses out of a universe of 3453 restaurants. This sample provides a confidence level of $95 \%$ and a confidence interval of $5 \%$. In addition, we webscraped data from TripAdvisor to assess its coverage in Lisbon. This study reveals that there are different forms of online presence and engagement which have generated cyberdivisions.

Keywords: cyberdivisions; cyberspace; VGI; digital platforms; platform economy

\section{Introduction}

Economic organisation in cities is increasingly based on the use of digital platforms as intermediaries of different actors. In this context, firms are adapting their business models, moving towards a more open model based on a platform economy logic [1-4]. The services made available through digital platforms have been the central element in the discussion of the transition from a logic based on goods to a logic based on services. For Lusch and Vargo [5], service is the fundamental basis of exchange between economic actors and value is always co-created by the multiplicity of actors in an ecosystem of service exchange. However, the transition toward an economy increasingly based on ecosystems integrated into platforms has created specific challenges for different economic sectors, as some firms struggle to integrate their services into platform ecosystems to remain competitive. While the fact that more and more companies are based on the principles of the platform economy has provided remarkable innovations in the development of products and services, it is still necessary to remain attentive to the differentiations that platforms make.

Such differentiation can be observed in the platforms themselves. Graham [6] called for our attention to the emergence of cyberdivisions, that is, inequalities in the various forms of using and appropriating cyberspaces. Such differences have been underexplored 
as the majority of scientific studies on the digital divide focuses on the issue of internet access and data coverage [7]. With this in mind, this paper aims to explore the making of cyberdivisions under the platform economy. We argue that the design of volunteered geographic information (VGI) within digital platforms is generating cyberdivisions in the urban economy. While previous studies have shown that the way that algorithms are structured, rank and map information in cyberspace shapes the representations of place and the way that individuals navigate and understand virtual and physical places, there is still little insight as to how the design of digital platforms generate cyberdivisions under the platform economy [8-12].

We substantiate our argument through an empirical study of the impact of the design of the digital platform TripAdvisor in the restaurant sector in the city of Lisbon, Portugal. In this study, we conducted an online survey to restaurant firms in the city of Lisbon, which allowed us to identify the cyberdivisions that stem from the types of registration available for firms in TripAdvisor. We obtained 385 responses out of a universe of 3453 restaurants. This sample provides a confidence level of $95 \%$ and a confidence interval of $5 \%$. On the other hand, we also conducted webscraping to have an overview of TripAdvisor's coverage in Lisbon.

This study expands knowledge on the geographical dimension of the platform economy. We unveil how the design of VGI-namely through the different types of registration within TripAdvisor-differentiates firms according to their present and future engagement with digital platforms. Such differentiation has direct and indirect effects for each restaurant firm. These effects unfold both in the digital and the real world.

This paper is further divided into four sections. First, we briefly review existing literature on cyberdivisions and discuss the importance of the concept under the platform economy. Secondly, we present the methodology of our empirical study. Thirdly, we present the results of our survey, showing how the relationship between the type of registration in TripAdvisor and the different levels of engagement between firms and digital platforms in Lisbon generates cyberdivisions, highlighting the geographical dimension of these divisions. Lastly, we conclude our paper by calling for greater attention to the relation between the design of platforms and the success of the urban economy.

\section{The Cyberdivisions of the Platform Economy}

Firms become more dependent on digital communications as data is increasingly playing a central role in how firms relate with workers, customers and other actors. In this context, digital platforms emerge as a new business model. Platforms can extract, manage, and analyse large amounts of information and integrate a large number of firms [13]. The new services resulting from the existence of digital platforms have been enticing several existing companies to associate themselves to or to create platforms. More importantly, platforms as digital infrastructures assume the role of intermediaries and enhance network connectivity with consumers, advertisers, producers, suppliers, among others [1,3,4]. Grabher et al. [2] argue that we are facing a new moment of convergence in which the central elements are open firms and increasingly active stakeholders. Instead of producing or innovating in isolation, firms are seeking to exchange external services to co-create value and innovation. In this sense, firms are looking for new ways to create and develop services and products in an open logic, integrated into ecosystems constituted by different elements. Therefore, digital platforms are characterised by an assemblage of people, processes, interfaces and artifacts $[14,15]$. Indeed, digital platforms are increasingly important in value co-creation processes given their power to reach different actors of any place in the world [16,17], leading to a new economic context: platform capitalism or the platform economy [4,18-20].

While digital platforms are creating new opportunities for firms, several challenges are also emerging. The design of digital platforms, specially VGI-based platforms, has allowed the creation of different levels of online engagement [21]. While some firms adhere to platforms willingly, customers and other online actors can also share and create information 
about a firm on many platforms. As a result, VGI platforms entail different forms of online presence for firms, which can become problematic in some cases.

To understand these phenomena, we must direct our attention to the design of platforms, which leads us to the concept of cyberspace and cyberdivisions. The concept of cyberspace can be defined as an alternative dimension that can be accessed and used by those with an internet connection. Any space within the internet can be understood as part of cyberspace [6]. For classical authors, cyberspace was a shared virtual reality and a consensual hallucination [22]. However, geographers explored the notion of cyberspace beyond the idea that it transcends space and makes geography insignificant [23-25]. Instead, it was argued that cyberspace entailed a new spatial dimension for geography [26]. As communication technologies and opportunities for production and consumption have a strong geographical bias [27-30], cyberspace has its own geographies and irregular topologies [31,32].

Kitchin [33] suggests that cyberspace has a symbiotic relationship with geographic space. In the same line of thought, Cohen [34] states that cyberspace should not be a separate space, but an extension of daily spatial practice, characterised by being constantly created and recreated through individualised interactions. Graham and Zook [10] argue that the internet should not be understood as an abstract space but as a real network of individuals and information that forms heterogeneous geographies. Indeed, the global village discourse has faced serious criticism from the perspective of the digital divide, given that globality would require complete coverage.

In this sense, Graham [6] argues that the digital divide is more than a statistical division between individuals and places: it is an existential division, as many remain in the physical background without access to the virtual world. Graham also argues that the formulation of the concept of the digital divide must go beyond the distinction between those who are connected and those who are not. Claiming that the digital divide should not be understood as an abyss that separates the individual from communication, knowledge and interaction, Graham argues that we should consider two types of divisions. On the one hand, there is the physical division that separates individuals from cyberspace. This division refers mainly to a question of resources, that is, the means of entry to cyberspace. On the other hand, he proposes the term cyber divides to refer to the constraints to interaction within cyberspaces. Graham draws attention to the fact that even if individuals have the means to enter cyberspace, other divisions might surface in cyberspace. He highlights the importance of governmental and corporate actions of content restriction and cultural differences such as language barriers as makers of cyberdivisions. Others also have highlighted issues of digital literacy, including geo-spatial data literacy [35].

However, it must be added that platform capitalism is also generating cyberdivisions as its algorithms organise information in ways that affect online visibility. For instance, studies on search engines have shown that processes of classification and hierarchisation of content not only make some kinds of content more visible but also render other contents invisible in the online environment [12]. This fact becomes even more noteworthy if we take into account that studies have indicated that most users only see the first ten search results [36] and that virtual representation has a profound impact on the way that individuals navigate and understand both virtual and physical places $[9,10,12]$.

In this context, the inequalities of online visibility generate divisions for firms. For instance, it is no longer enough for entrepreneurs to have a well-designed website, if the hierarchisation and other processes inherent to search engines do not offer significant visibility. As a result, digital divides remain, despite the presence in the virtual environment, due to the lack of visibility. In the next sections, we will show how these cyberdivisions are generated under the context of the platform economy, highlighting the role of platform design in the making of cyberdivisions. 


\section{Materials and Methods}

Lisbon in TripAdvisor

The data collection process was performed through a webscraping process [37] that allows to automatically extract a great amount of data from public websites. To proceed with this routine, a WebScrapping function was developed in $\mathrm{R}$. To obtain restaurant data location from TripAdvisor, the first step was to get the exclusive link from each restaurant indicated as located in Lisbon using a WebScrapping function. The exclusive link is the unique URL that allows to access a webpage, inside TripAdvisor, that contains only single restaurant information, which can be considered its profile inside the platform. In this first process, we obtained 3989 links, referring to the 3989 restaurants placed in Lisbon. Due to the platform dynamic, other restaurants might be registered since this period, being this number (3989) representative from all listed restaurants given the collection moment.

For each of these restaurants' links, we developed another WebScrapping function, aiming to collect, from each link, some restaurant data regarding the location. The data collected was street address and zip code.

We subjected the database to a validation procedure to guarantee the necessary conditions for statistical and cartographic analysis. The procedure entailed three steps. The first step comprised the verification of the postal code of every establishment. We found 795 establishments with incomplete or absent postal codes. The missing postal codes of the restaurants were acquired by searching their address in Google Maps. The second step was the verification of the duplications of restaurants in the dataset. TripAdvisor's platform is vulnerable to duplication, given that any user can insert establishments voluntarily and different users might insert the same establishment under different names. We excluded duplications by identifying the duplications of postal codes and door numbers. 382 duplications were found and deleted from the dataset. The last step was dedicated to ensuring that the restaurants in the database were indeed located within the Lisbon municipality. 155 restaurants were deleted from the dataset after we verified that they were located in neighbouring municipalities. Our final dataset includes a total of 3452 validated restaurants. We matched the zip code and door number data with the database of matching coordinates in ArcGIS, to map the TripAdvisor coverage.

The map of Figure 1 shows TripAdvisor's coverage (density $/ \mathrm{km}^{2}$ ). The higher level of coverage in TripAdvisor (61.01-122) is located predominantly in the historical city centre. Important areas of retail, consumption and culture are located in this area, namely, in Baixa-Chiado, Cais do Sodré and Martim Moniz, where several restaurants or similar establishments are also located [38]. In the last decade, this area has been transformed by gentrification and touristification processes, which had important effects in several residential neighbourhoods such as Alfama, Mouraria and Bairro Alto, namely an increase in the number of establishments and local accommodation, hostels and hotels [39-42].

The levels of coverage decrease slightly (23.01-65) in the modern city centre of Lisbon (Areeiro, Arroios, Avenidas Novas, Campo de Ourique, Santo António and São Vicente) where the residential function is more significant than the economic one. This area displays average values and contains several trendy middle-class residential neighbourhoods with small shopping and restaurants or similar establishments districts. The levels of coverage decrease further in some areas in the vicinity of the historical (Estrela) and the modern city centre (Alvalade and São Domingos de Benfica). The parish of Parque das Nações is the exception to the monocentric spatial trend. Parque das Nações is a large regenerated waterfront located in the site where the 1998 World Exhibition was held, was converted into a campus for private corporations and public institutions with important retail facilities and a residential area designed for a wealthy class with a high purchasing power. For this reason, several establishments are located in this area. Moreover, Parque das Nações is an important intermodal transport centre with several modes of transport, including urban bus, subway, train, long-distance train and direct subway connection to the airport. The density of restaurants or similar establishments in TripAdvisor can also be explained by the Vasco Da Gama regional shopping mall which is located in this parish. 


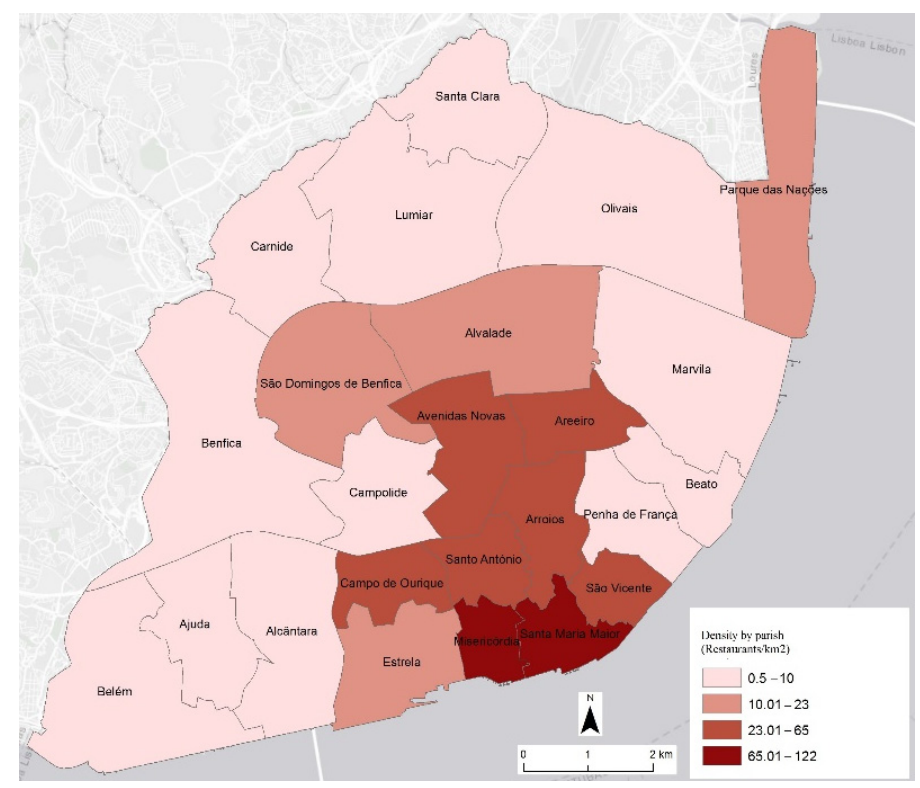

Figure 1. TripAdvisor's coverage of the restaurant sector in the city of Lisbon (density by parish, restaurants $/ \mathrm{km}^{2}$ ).

The areas with the lowest coverage values (0.5-0.10) match the most socially and economically deprived areas of the city. The Eastern waterfront of Lisbon (Beato, Marvila and Penha de França) is traditionally composed of industrial areas in which there is a coexistence between working-class neighbourhoods and social housing projects. While some of the inactive industries have been converted into nightlife establishments and restaurants and some of the industry is still active, brownfields dominate this area [43]. The low values of the peripheral parishes in the Northern and Western zone of the city are related to the dominance of the residential function, as well as the presence of some large non-residential areas. For instance, the values of Santa Clara can be explained by the location of Lisbon's airport, and the values of Benfica can be explained by the presence of the city forest-Monsanto. Regarding some parishes such as Santa Clara and Ajuda, we must also refer to the presence of a considerable set of social housing built in the 1990s under the Programa Especial de Realojamento (Special Rehousing Program) [44,45].

Survey

In this study, we conducted an online survey aimed at restaurant firm managers who are listed on TripAdvisor in the municipality of Lisbon. The survey was conducted during February and March 2020. We obtained 385 responses out of a universe of 3453 restaurants. However, we believe that if we had conducted this survey a few months ahead, we would find more registered restaurants and similar establishments on TripAdvisor given that the recent literature review is showing that platformisation processes accelerated in the pandemic context. This sample provides a confidence level of $95 \%$ and a confidence interval of $5 \%$. Some districts have a low number of responses, which can be explained by the very low coverage that TripAdvisor has in some areas of Lisbon, as we can see in Figure 1.

The main objective of this survey was to identify the different levels of interaction between restaurant entrepreneurs and TripAdvisor. Given our interest in understanding how the design of VGI within digital platforms is generating cyberdivisions in the urban economy, a major interest in this survey was to relate the type of registration in TripAdvisor with the different levels of online interaction. Firms can be registered in TripAdvisor in two ways. First, they can be added by the firm manager, and this type of registration not only allows firm managers to engage in customer relation management tasks, but also provides access to several B2B services, including table reservation, takeaway and delivery services. Secondly, they can be added by a platform user, usually, a restaurant customer who wishes to share her or his consumption experience. In this case, the restaurant will be represented 
in the platform, but the firm owner cannot manage the relationship with customers. Our results show that this design feature of the TripAdvisor platform leverages different types of cyberdivisions. Before we delve into the survey's results in greater depth, we present a brief characterisation of the survey sample.

This survey covered different types of restaurant establishments, the most predominant being the restaurant $(65.7 \%) .18 .2 \%$ of respondents reported having a restaurant with a bar and $12.7 \%$ of respondents reported having a café/pastry shop. With more residual percentages, some respondents own bars $(2.1 \%)$ and snack bars (1.3\%). Only $3.4 \%$ of all respondents claim to be part of a franchise chain and these are mostly restaurants. Regarding the opening year, $62.2 \%$ of respondents opened their establishment between 2010 and 2020, 12.4\% opened between 2000 and 2010, 4.8\% opened between 1990 and 2000, 10.3\% opened between 1976 and 1990 and also 10.3\% have their establishment as before 1976. Figure 2 shows the spatial distribution of the total of respondents, using the natural breaks classification. We choose the natural breaks classification, in which classes are created according to the natural groupings inherent in the data, maximising the differences between classes. That is, the breaks that divide the classes are set in points where there are larger differences in the data values.

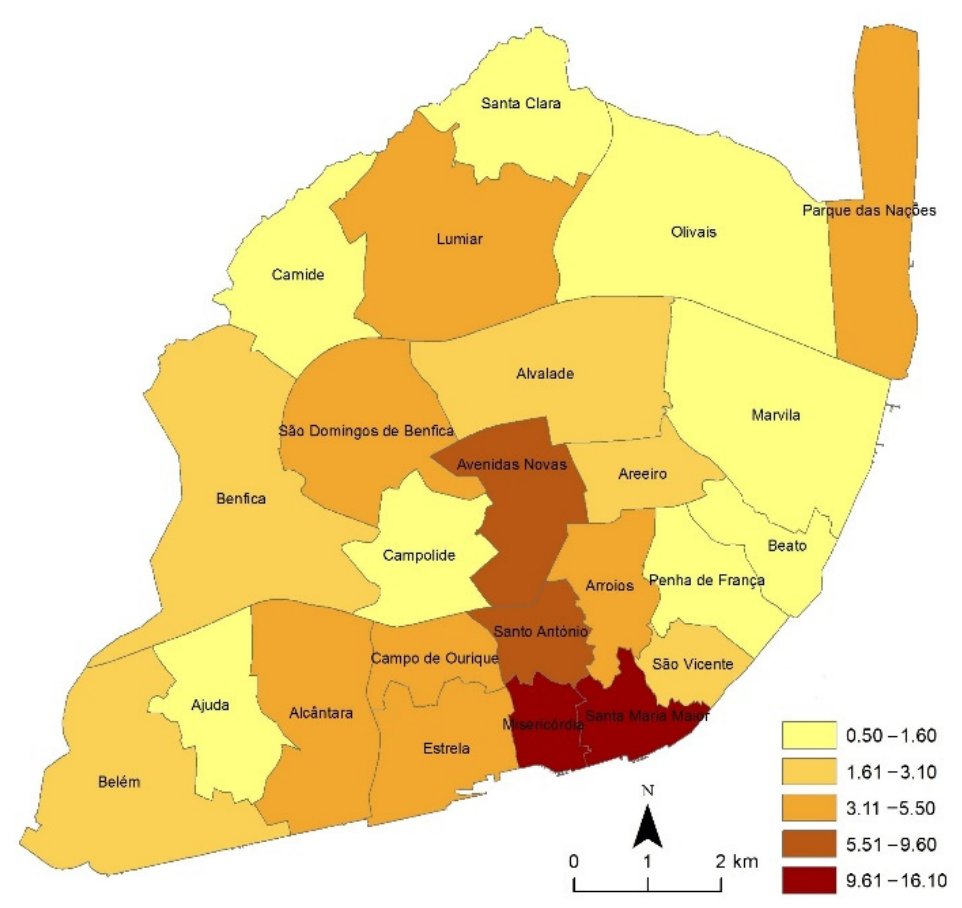

Figure 2. Spatial distribution of the sample in the municipality of Lisbon (\%).

In terms of the spatial distribution of the sample (Figure 2), there is a greater concentration in the historic core of the city (42.6\%), especially in the parishes of Misericórdia and Santa Maria Maior. The modern city centre, where the parishes of Santo António and Avenidas Novas stand out, also displays a high percentage of respondents (28.8\%). This is not surprising as the historic core and the modern city centre have the highest concentration of restaurant establishments in the municipality of Lisbon. The peripheral, mostly residential parishes, have a lower concentration of restaurants, often limited to a few neighbourhood main streets. These areas comprise $28.6 \%$ of the sample. It must be noted that the parish of Parque das Nações differs from all others in this group, as can be seen in the map in Figure 2, due to its greater offer in retail and services. Parque das Nações—a large urban regeneration project associated with a mega-event in the 1990s—is a relatively new centrality in the city of Lisbon. 


\section{Results}

4.1. Type of Registration in TripAdvisor, Its Spatial Dimension and Relation with the Different Levels of Engagement with Digital Platforms

TripAdvisor's design allows the registration of establishments by any type of user, which translates into different levels of online engagement. For this reason, this survey sought to identify which establishments were registered by the owner and which were registered by users, as this can generate different effects on each establishment. The survey revealed that $52.5 \%$ of the restaurant managers registered their establishment on the platform (Figure 3). These are likely managers who play a more active role in online activities and who, as a result, have registered their establishment on TripAdvisor. On the other hand, 38.7\% claim they were not responsible for this registration, which indicates that their establishment was registered on TripAdvisor by users. It may also indicate that these managers have a less active role in online platforms in general when compared to the previous ones. This does not imply that this group is completely offline from the digital sphere, but they may in fact have a lower level of interaction and engagement than the group mentioned above. In addition, $8.8 \%$ of the survey respondents are unaware of their placement on TripAdvisor, which indicates that not only their establishment was registered by users, but also that these managers display a higher level of detachment than other respondents. In this sense, their level of involvement and knowledge with digital platforms may be even lower when compared to the two remaining groups.

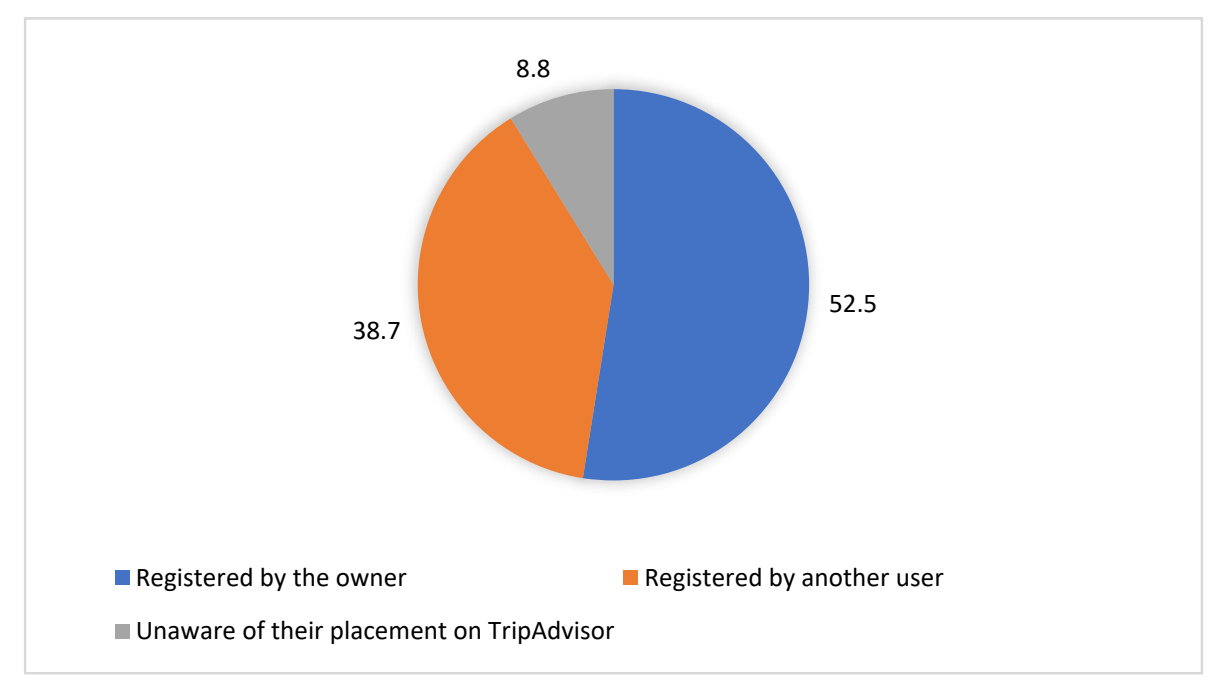

Figure 3. Type of registration in TripAdvisor (\%).

To explore the relation between the type of registration and the different levels of involvement between firm owners and digital platforms, in the next subsections, we will explore the spatial distribution of these firms and the knowledge about digital platforms of each group.

\subsubsection{Spatial Distribution}

The maps in Figure 4 show the spatial distribution of the respondents' establishments according to the type of registration in TripAdvisor. The establishments that were registered by their owner are mainly concentrated in the parishes of Misericórdia and Santa Maria Maior (historic core), followed by some parishes in the modern centre such as Santo António and Avenidas Novas (Figure 4a). On the other hand, the map that represents the establishments registered by users (Figure $4 \mathrm{~b}$ ) shows a more heterogeneous spatial distribution in which the highest values can be found across the different areas of Lisbon. The parishes in the historic core are still those with the highest concentration of establishments, but we can also find high values in some peripheral parishes in the North Zone, namely Lumiar and São Domingos de Benfica. Lastly, the map of establishments 
in which the owner does not know if the firm is represented on TripAdvisor (Figure 4c) displays a radically different spatial distribution when compared to the two previous maps. The highest concentrations are found in peripheral parishes in the North and Western areas of the city, while the parishes in the historic core barely have any establishment in this category.
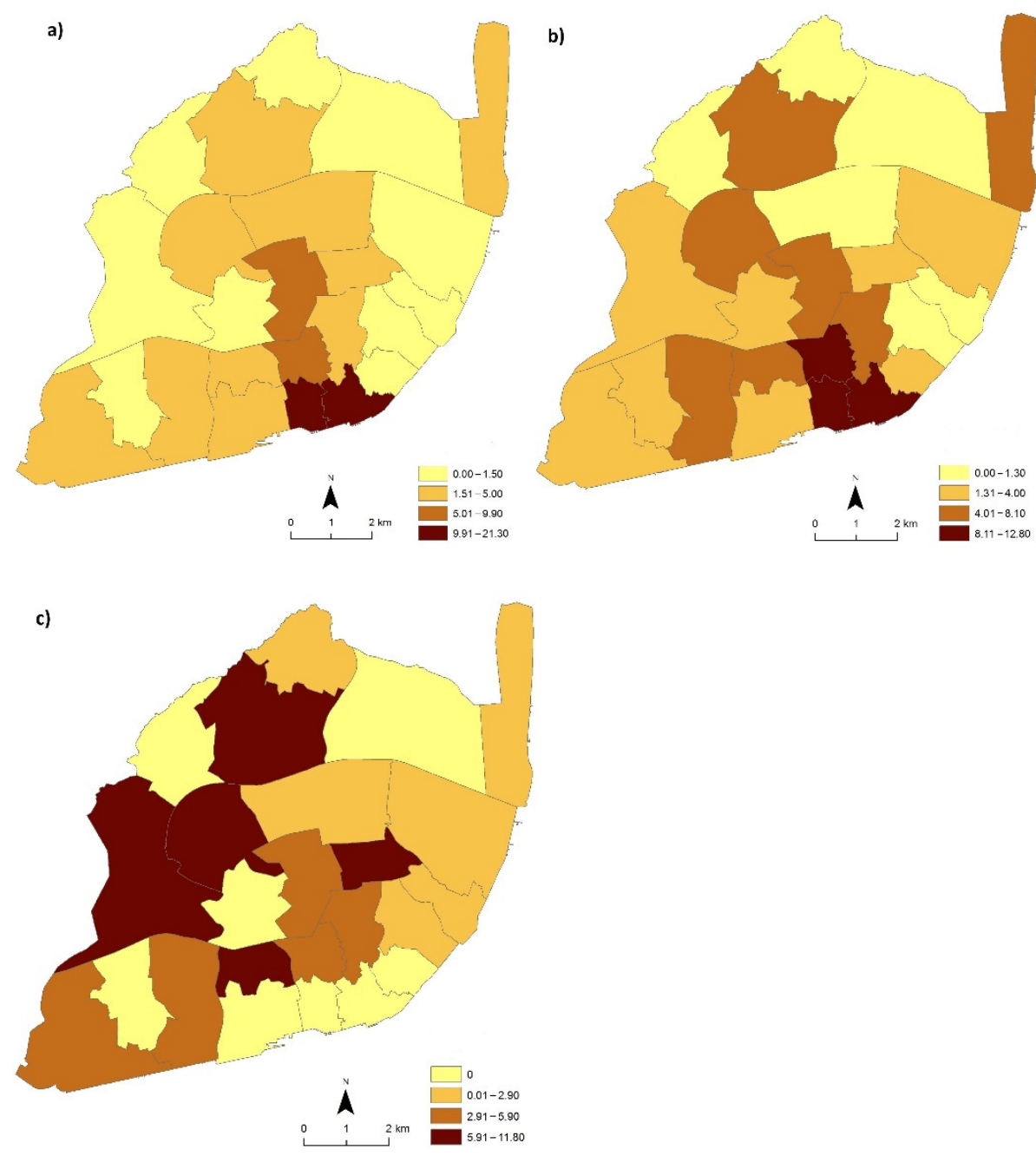

Figure 4. Spatial distribution of the sample according to the type of registration (\%). (a) Registration made by the firm; (b) Registration made by the user; (c) Unaware of registration.

These findings indicate that restaurant firm managers with a greater connection to digital platforms are mainly found in the most central areas of the city. while firms with a low connection to platforms are more likely to be located in peripheral areas. More importantly, the trends found in these maps indicate that the design of the platform does have a spatial dimension. Such dimension seems to be related to the functions of the different city areas. On the one hand, restaurant managers located in the historic core and the modern centre must deal with higher competition, as the concentration of restaurants in these areas is higher than in other areas of Lisbon. Moreover, these are areas in which the tourism component (mainly in the historic core) and services (mainly in the modern city centre) are extremely relevant. In this sense, while demand is high in these areas, so are the challenges and competition. These contextual conditions might explain the greater adoption of online strategies in business models in these areas. On the other hand, Figure $4 \mathrm{~b}$ indicates that the willingness of users to share information is transversal to all parishes in Lisbon, despite a slight difference between the historic core and the most peripheral areas. In this sense, content-sharing by users is an action that comes from wider geography. 


\subsubsection{Knowledge and Engagement with Platforms}

Having established that the design of VGI within TripAdvisor has a spatial dimension, we now turn to understand the cyberdivisions generated by this process. Different types of registration lead to different forms of engagement with digital platforms, which can turn into different intensities of use. The results of our survey provide some clues about the knowledge and engagement of restaurant firm owners with the digital world. To understand the role of the design of VGI in generating cyberdivisions, we continue to segment our analysis of the survey data by the type of registration of firms.

The group of respondents who registered their establishment on the TripAdvisor platform (52.5\% of the total) take on an active role in the digital sphere. As can be seen in Figure 5, these respondents report that they are registered, in addition to TripAdvisor, on digital platforms such as Zomato (91.6\%), The Fork (51.5\%), Yelp (17.3\%), FourSquare $(12.9 \%)$, among others. This indicates that these respondents have extensive knowledge about the existence of platforms in the restaurant sector.

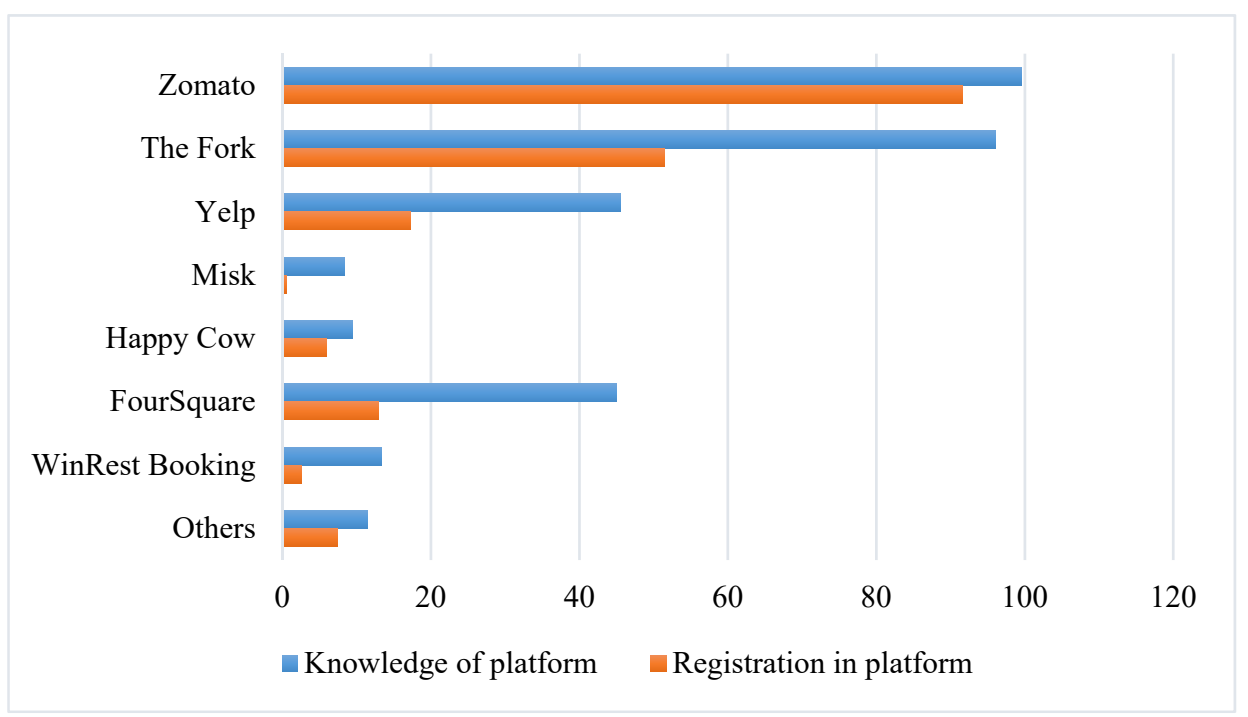

Figure 5. Platforms that managers know and platforms in which the firm is registered (\%). This data encompasses firms that registered their establishment in TripAdvisor.

The group of respondents who were not responsible for registering their establishment on TripAdvisor (38.7\% of the total) are registered in fewer digital platforms (Figure 6). Those that are registered in digital platforms have chosen the most popular ones: $54.4 \%$ are registered in Zomato, 24.2\% are in The Fork and 8.7\% have registered in other platforms. It is noteworthy that there are no registrations made on platforms such as Yelp, Misk or FourSquare. However, it is important to mention that even though they are registered on fewer platforms, $98 \%$ of this group of entrepreneurs mention that they know Zomato, $81.9 \%$ know The Fork, 42.3\% know Yelp and 30.9\% know FourSquare (Figure 6). This discrepancy between knowledge and registration in platforms indicates that lack of knowledge is not the main explanation for their low engagement with the platform economy. Other reasons should be taken into account when questioning the non-presence of these entrepreneurs on certain digital platforms, such as the lack of training in the use of platforms, the spatial, social and economic context, or views against the model that digital platforms promote.

The group of respondents who are unaware of the representation of their establishment on TripAdvisor ( $8.8 \%$ of the total) demonstrate knowledge about platforms (Figure 7 ) similar to the previous group, despite not using platforms. Although these respondents do not know if their establishment is listed on TripAdvisor, $79.4 \%$ of these individuals claim to know this platform. Once again, this shows that the knowledge of digital platforms does not determine platform engagement. Nevertheless, it is noteworthy that $20.6 \%$ of respondents in this group who do not know TripAdvisor at all. 


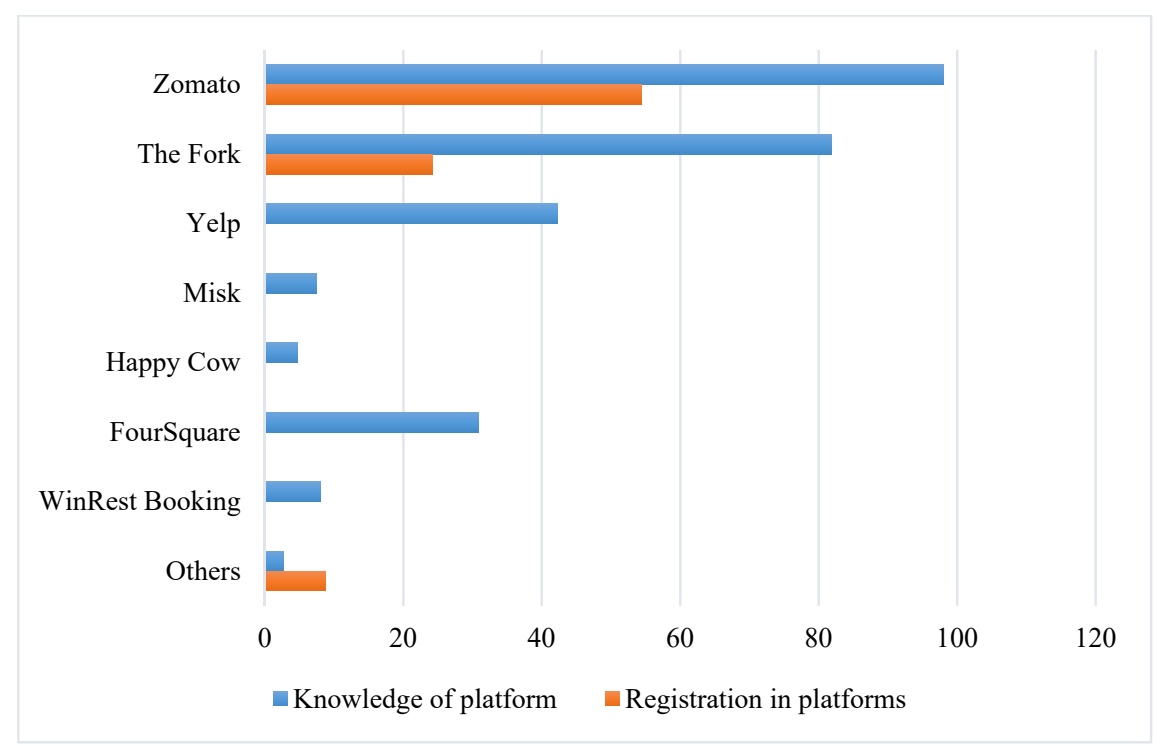

Figure 6. Platforms that managers know and platforms in which the firm is registered (\%). This data encompasses firms registered by users in TripAdvisor.

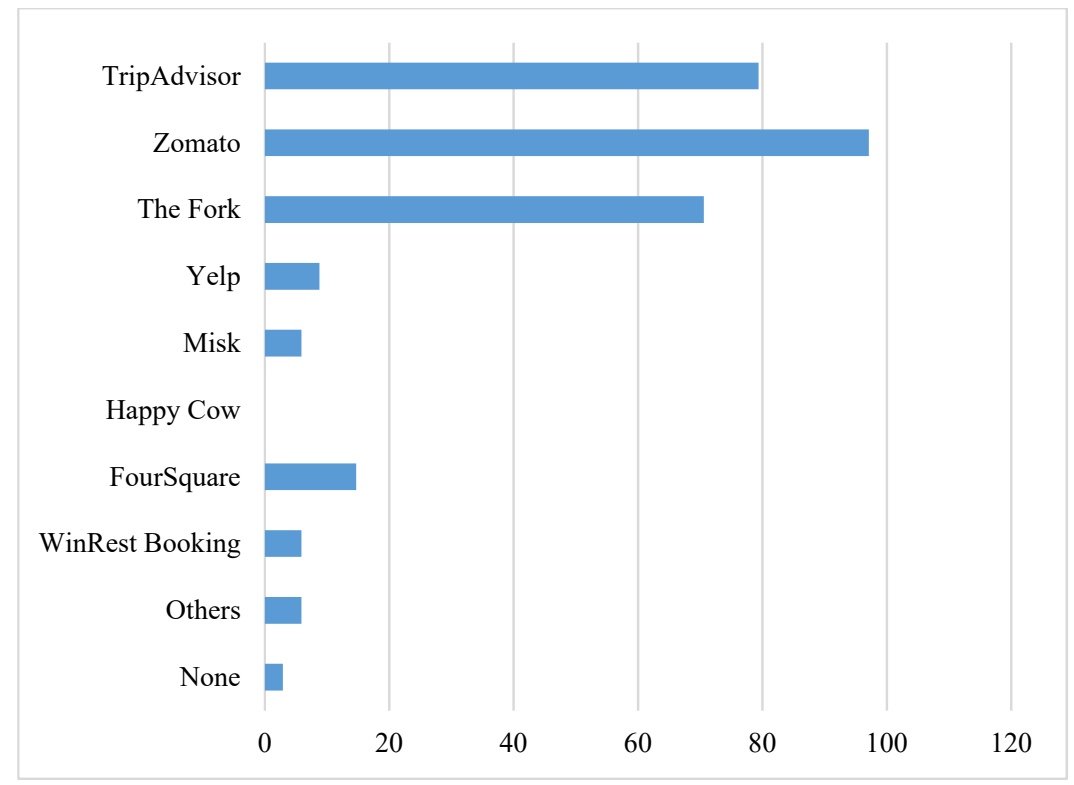

Figure 7. Platforms that managers know (\%). This data encompasses firms that do not know if they are registered in TripAdvisor.

When asked if they are planning a greater involvement with digital platforms, most respondents stated that they intend to devote more attention to this. However, once again, the type of registration differentiates the managers' responses. $68.8 \%$ of firm managers who registered their establishment on TripAdvisor state that they would like to register on more digital platforms in the future. Contrariwise, only $27.5 \%$ of firm owners who know they are on TripAdvisor, but were not responsible for their registration, are willing to register on more digital platforms. Interestingly, $61,8 \%$ of the respondents who do not know if their business is represented on TripAdvisor state that they are willing to integrate their firm in platforms in the future. While the first group is at a more advanced stage of digital expansion and wishes to continue investing in this path, this latter group-which has little involvement in the platform economy-shows some willingness to invest in this area.

In sum, we have seen that the design of VGI within TripAdvisor has a spatial dimension and that such design also differentiates firms according to their present and 
future engagement with digital platforms. In the next section, we highlight the significance of these cyberdivisions as we analyse the geographies of each type of registration in greater depth.

\subsection{The Geographies of Firms Responsible for Their Registration on TripAdvisor}

The firm managers responsible for their registration on TripAdvisor have a clear idea of whether other establishments around them are also included in this platform. About $35 \%$ of the respondents mention knowing that more than 10 establishments around them are registered on TripAdvisor and 21\% mention knowing that at least between 1 to 5 establishments are registered. This reveals that there is some concern with the online presence of neighbouring establishments, which can be considered a competitive factor. In this sense, the growing adhesion of restaurant establishments to digital platforms can become a driving factor for others in the same geographical area to go online as well.

While most respondents say they did not feel pressured to join TripAdvisor (55\%), there are $38 \%$ who say they did. These data point to a growing awareness that digital platforms play a relevant role in the restaurant sector. The fact that these managers are aware of online competition in their geographical area, as well as the fact that there is a considerable percentage of firm managers that feel pressured to be online, indicates that there is a clear notion of the importance of using digital tools. However, it is also necessary to highlight those who show a lack of interest regarding digital competition, given that $30 \%$ of these respondents are unaware of whether their neighbouring establishments are on TripAdvisor.

These managers have a positive perspective on the benefits of the platform economy. The graph in Figure 8 indicates that few managers in this group consider their use of TripAdvisor as "not at all positive" or "not very positive". In general, online presence in this platform is understood as positive, as $31.7 \%$ consider that TripAdvisor has been "very positive" and $12.4 \%$ consider it "extremely positive" (Figure 8 ). These results may explain why $55.4 \%$ of respondents state that they "no disadvantages" in being on TripAdvisor (Figure 9). These firm managers are more conservative regarding the advantages of engagement with digital platforms. Most of the advantages that TripAdvisor may offer are considered by these firm managers to be "relatively positive" (41.1\%). The difficulty in measuring the effects of digital platforms, which has been reported in the existing literature, may be a factor that explains this perspective [5,46]. It is difficult for these firms to measure how many patrons were reached through the platforms or how much online visibility has increased, although respondents have a perception that they are more present in the digital sphere. When asked about the main disadvantages, these managers highlight the negative reviews $(19.3 \%)$ as the main disadvantage, followed by digital competition $(14.9 \%)$, low online rating (7.9\%) and fake reviews (6.4\%).

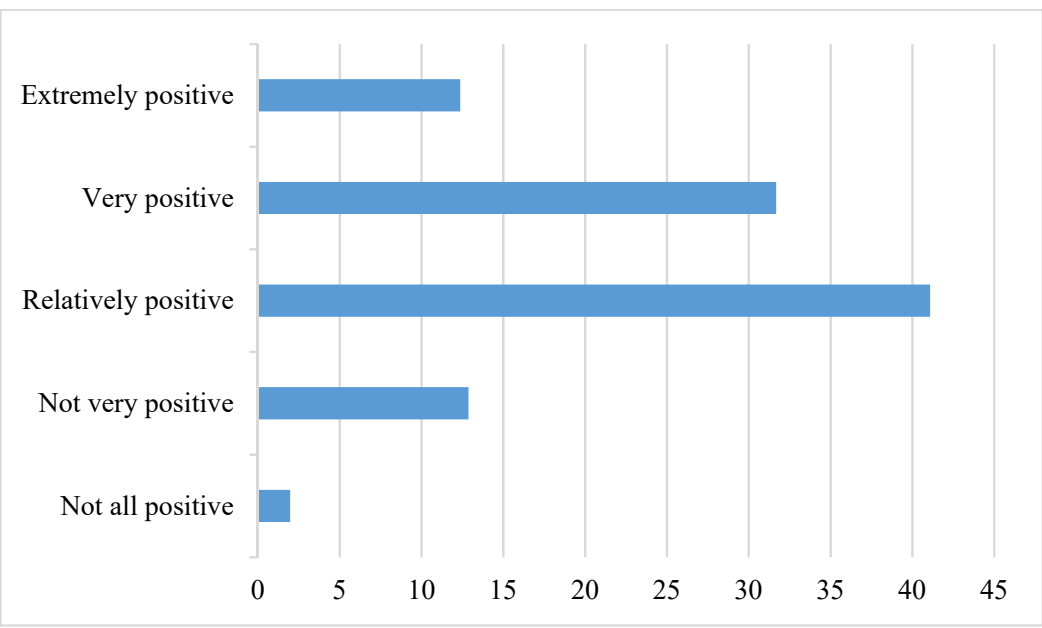

Figure 8. TripAdvisor's contribution toward firm success (\%). 


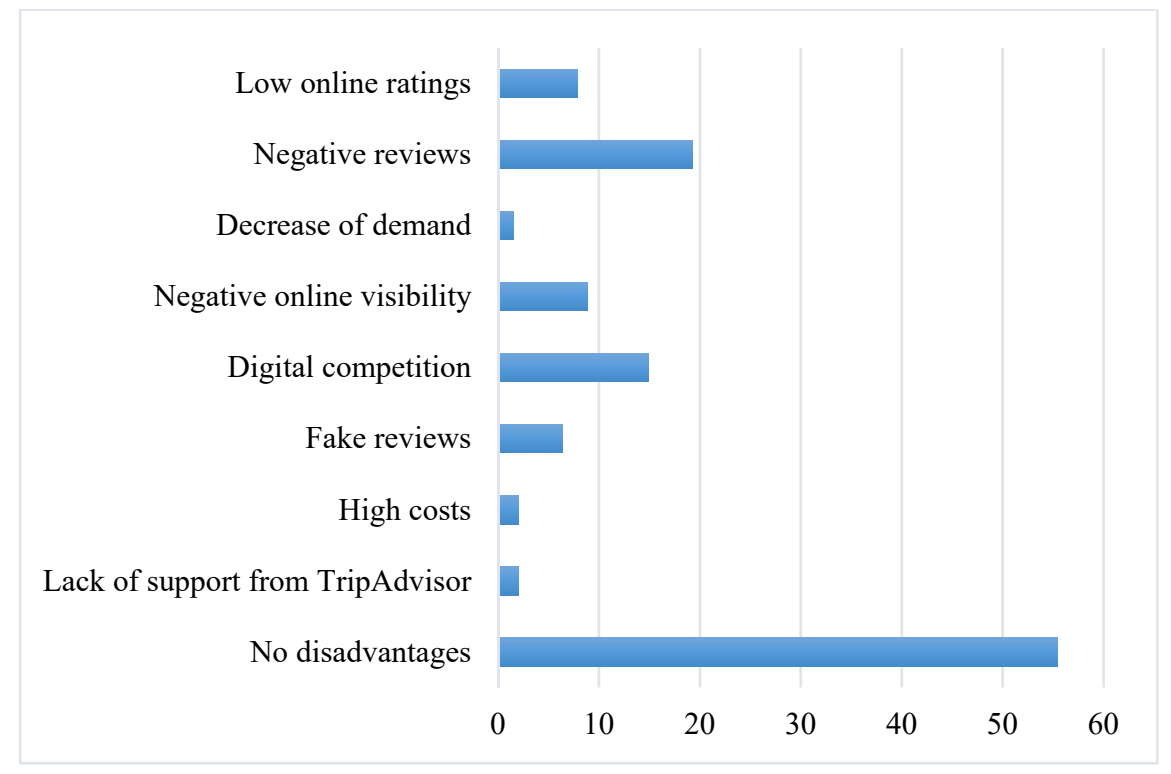

Figure 9. Disadvantages of registration in TripAdvisor (\%).

\subsection{The Geographies of Firms Not Responsible for Their Registration on TripAdvisor}

The results of our survey reveal that a significant percentage of respondents were not responsible for registering their establishment on TripAdvisor (38.7\%). Despite this, when asked to evaluate the impact of their presence on this platform (Figure 10), 30.2\% of these firm managers' report that it has been "extremely positive", $28.2 \%$ state that it has been "very positive" and $26.2 \%$ state that it has been "relatively positive". Therefore, these managers understand TripAdvisor as an advantageous online platform. These answers may be related to the indirect effects of the platforms [5], as respondents believe that information shared by customers can be beneficial to their business. On the other hand, the possibility that these managers might not have a real notion of the most adverse effects of the platform must be raised. It should be noted that $48.3 \%$ of these managers stated that they do not know if they were registered by users on platforms other than TripAdvisor. This suggests that there might be a lack of clear notion about the real effects of being on digital platforms.

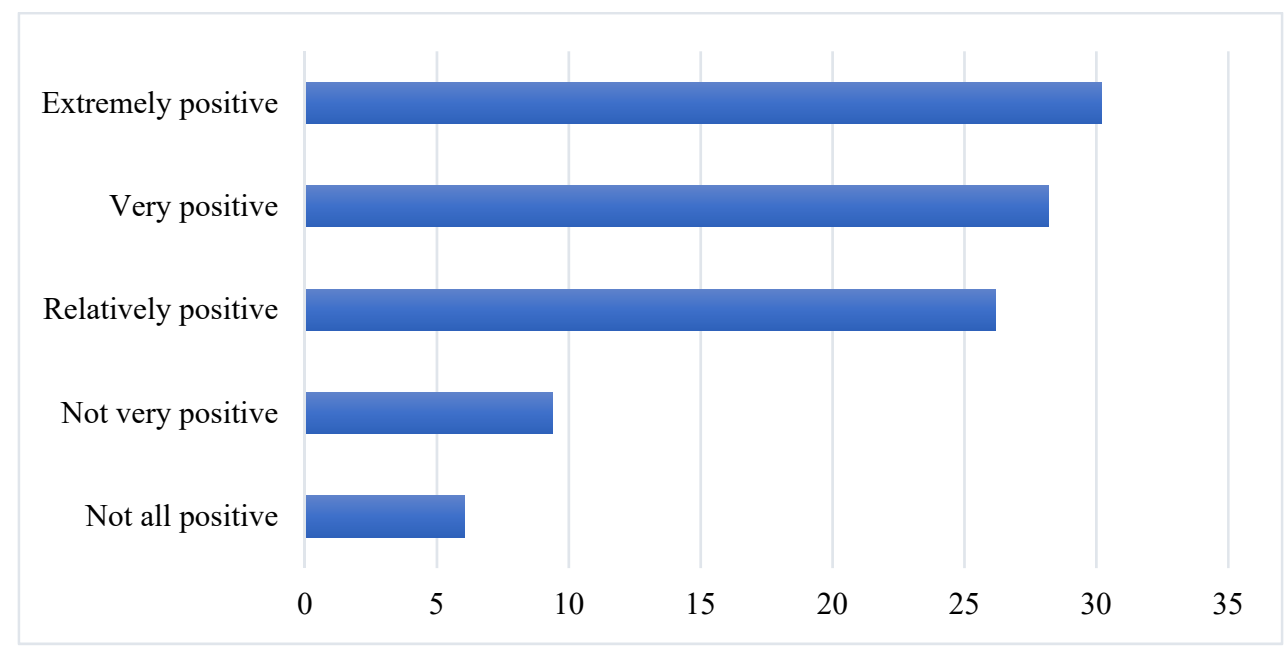

Figure 10. TripAdvisor's contribution toward firm success (\%).

Managers in this group tend to be more passive regarding their participation in digital platforms, not only because they are not responsible for their registration on TripAdvisor, but also because they are registered on a reduced number of platforms. Although this 
group of managers does not have a very active role in the digital sphere, they recognise that it is important to consider digital tools for the development of their business. This desire can be gauged by the evaluation that these managers make of the impact of TripAdvisor on their business. Although these managers are also conservative in their appraisal, their evaluation is positive on all topics considered. Most respondents have mentioned that TripAdvisor has contributed in a "slight" way toward online visibility, advertising, greater demand, greater proximity to the customer, better feedback, understanding improvement possibilities and evaluation and rating (Figure 11). Although they mostly consider that TripAdvisor has contributed in a 'slight' manner to improve their business, these results may trigger a greater desire for digital engagement since they identify positive effects despite not having a very active role in the digital environment.

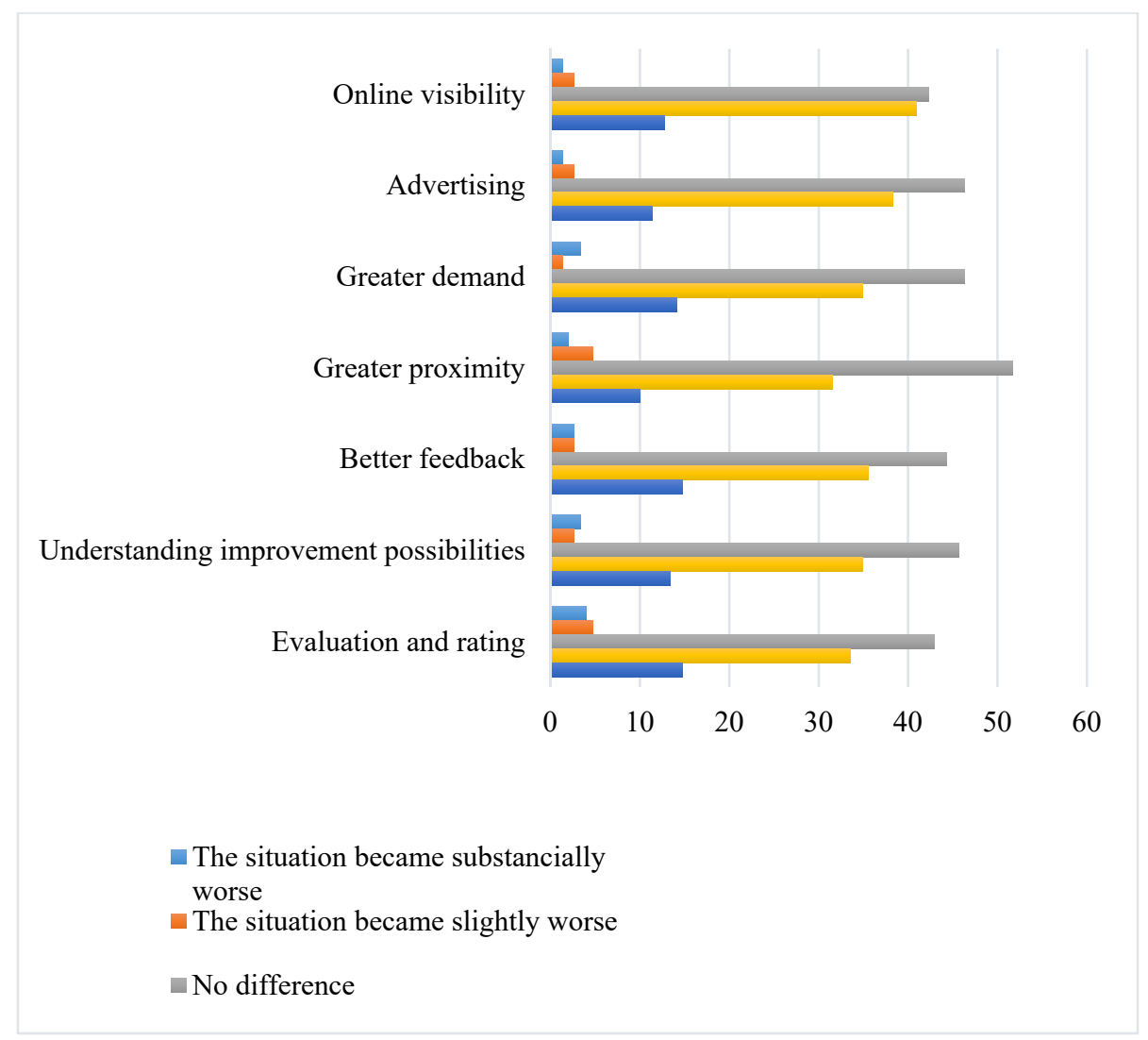

Figure 11. TripAdvisor's advantages for restaurant businesses (\%).

\subsection{The Geographies of Firms Unaware That They Are Represented on TripAdvisor}

Finally, it is worth mentioning the group of firm managers that have their establishment registered in TripAdvisor by users but are unaware of it $(8.8 \%$ of the total number of respondents). These data are important because they show that there is a percentage of firm managers in the Lisbon restaurant sector that do not have any kind of perception about their online presence on TripAdvisor. As a consequence, they are also unaware if their local competition is present in digital platforms and how they compare in the online realm. Also, for the same reason, these firms' owners cannot make a proper assessment of the impact that their registration on TripAdvisor has been making on their business.

Interestingly, this is the group of respondents who have been most invited to register with Zomato, as this is one of the platforms that invests more in seeking out restaurant establishments. More importantly, although this group is less engaged with digital platforms, these firm managers are familiar with them. As we can see, their percentages are close to the other groups. The fact that these firm managers know digital platforms and do not use them might indicate a lack of knowledge regarding how to use and take advantage of 
platforms, or it might also suggest that there is a deliberate non-involvement in the digital environment on the part of these managers.

\section{Discussion and Conclusions}

Our study has expanded knowledge on the geographical contours of the platform economy [4,22-24] by highlighting how the design of VGI within TripAdvisor differentiates firms according to their present and future engagement with digital platforms. In this sense, based on the type of registration, different firm ecosystems are built and these end up generating different direct and indirect effects for each restaurant establishment, although firm managers still have difficulties in assessing such effects. It must be underlined that such cyberdivisions have an important real-world spatial dimension. In this sense, TripAdvisor is not only a generator of different cyberspatialities within cyberspace, but also a conduit for the spatial differentiation of the urban economy through the cyberdivisions it produces.

We have seen that firm managers with a greater engagement with TripAdvisor are also very aware of their local competition, which might be explained by the fact that they are mostly located within the touristified historic core or the service-dominant modern city centre. In sharp contrast, firm managers with a lesser engagement tend to be less aware of local competition, which might also be explained by their tendency to be located in residential neighbourhoods in peripheral parishes.

This overlapping of cyber- and real word divisions is even more spatially significant if we consider that it might increase urban inequality. Cyber-excluded firms are unaware of the importance of the ecosystems that digital platforms establish, and thus the effects that may result from those ecosystems are not known by the managers of these firms, who are at the mercy of the content created in these platforms (comments, ratings, etc.) about their business. Opinions and information shared on platforms are unpredictable, meaning that these firms that do not choose not to be on TripAdvisor are exposed to the most varied types of comments and ratings given, and their managers do not have any control over the management of their page. In this sense, the indirect effects arising from user feedback and ratings can become harmful to the business. The opposite effect can also happen, because if there is very positive feedback, the firm might have advantages, albeit indirect, by being represented on the platform [21].

Lastly, it should be noted that cyberdivisions are also reflected in urban space by the classifications that are being assigned to each establishment. This generates, at the spatial level, economic and territorial differentiation in which certain areas of Lisbon have benefited from the cyber-divisions produced by TripAdvisor, as opposed to others that end up with a negative stigma.

These findings expand current knowledge on how information structured, ranked and mapped in cyberspace shapes the representations of place and the way that individuals understand virtual and physical places [8-10,12]. It particularly highlights the importance of such processes for the urban economy under the platform capitalism paradigm [1,3,4], which leads us to call for a greater engagement with the relation between platforms, cities and firms by geographers and other spatial scientists.

However, we also recognise limitations in this study. Our study identifies cyberdivisions, but does not explore the effects that such cyberdivisions might have on firms. Furthermore, we have focused on a specific type of platform design, and the cyberdivisions of other platforms must be explored. In this sense, we hope this study can be a starting point to explore the hidden divisions in cyberspace. In the near future, we need more information about these cyberdivisions and especially how they can affect firms positively and negatively. In this sense, we think that the next direction of this topic would be exploring the effects of VGI platforms over firms because, as we can see, some firms have no idea or control over what is happening in the digital world. Such studies can and should explore other research designs. In this study, we have designed our study to focus on the type of registration of the platform, but other studies might explore other variables such as the firm 
strategy, the manager's background, or econometric data. Furthermore, the combination of different research methods, including quantitative methods such as big data analysis and qualitative methods such as in-depth interviews, can provide a new perspective suited to understand the issue of cyberdivisions.

Author Contributions: Conceptualisation, Daniela Ferreira, Mário Vale and Renato Miguel Carmo; methodology, Daniela Ferreira; validation, Daniela Ferreira, Mário Vale and Renato Miguel Carmo; formal analysis, Daniela Ferreira; data curation, Daniela Ferreira; writing —original draft preparation, Daniela Ferreira; writing-review and editing, Daniela Ferreira, Mário Vale and Renato Miguel Carmo; supervision, Mário Vale and Renato Miguel Carmo All authors have read and agreed to the published version of the manuscript.

Funding: This work was supported by the Fundação para a Ciência e a Tecnologia [SFRH/BD/131253/ 2017]; and the Centre of Geographical Studies [UIDB/00295/2020], [UIDP/00295/2020].

Institutional Review Board Statement: Not applicable.

Informed Consent Statement: Informed consent was obtained from all subjects involved in the study.

Data Availability Statement: Data is not publicly available.

Acknowledgments: We wish to thank the special issue editor and four anonymous referees for their helpful comments and suggestions.

Conflicts of Interest: The authors declare no conflict of interest.

\section{References}

1. Bratton, B. The Stack: On Software and Sovereignty; MIT Press: Cambridge, MA, USA, 2015.

2. Grabher, G.; Ibert, O.; Flohr, S. The Neglected King: The Customer in the New Knowledge Ecology of Innovation. Econ. Geogr. 2015, 84, 253-280. [CrossRef]

3. Rochet, J.C.; Tirole, J. Two-Sided Markets: A Progress Report. The RAND J. Econ. 2006, 37, 645-667. [CrossRef]

4. Srnicek, N. Platform Capitalism; Polity Press: Melden, MA, USA, 2017.

5. Lusch, R.F.; Vargo, S.L. Service-Dominant Logic. Premises, Perspectives, Possibilities; Cambridge University Press: Cambridge, UK, 2014.

6. Graham, M. Time machines and virtual portals: The spatialities of the digital divide. Prog. Dev. Stud. 2011, 11, 211. [CrossRef]

7. Ferreira, D.; Vale, M.; Carmo, R.M.; Encalada-Abarca, L.; Marcolin, C. The three levels of the urban digital divide: Bridging issues of coverage, usage and its outcomes in VGI platforms. Geoforum 2021, 124, 195-206. [CrossRef]

8. Ferreira, D.; Vale, M. From cyberspace to cyberspatialities? Fennia 2021, 199, 113-117. [CrossRef]

9. Graham, M. Neogeography and palimpsests of place: Web 2.0 and the construction of a virtual Earth. Tijdschr. Voor Econ. Soc. Geogr. 2010, 101, 422-436. [CrossRef]

10. Graham, M.; Zook, M. Augmented realities and uneven geographies exploring the geolinguistic contours of the web. Environ. Plan. A 2013, 45, 77-99. [CrossRef]

11. Paiva, D. Experiencing virtual places: Insights on the geographies of sim racing. J. Cult. Geogr. 2015, 32, 145-168. [CrossRef]

12. Zook, M.; Graham, M. Mapping DigiPlace: Geocoded internet data and the representation of place. Environ. Plan. B Plan. Des. 2007, 34, 466-482. [CrossRef]

13. Bustamante, A.; Sebastia, L.; Onaindia, E. BITOUR: A Business Intelligence Platform for Tourism Analysis. ISPRS Int. J. Geo-Inf. 2020, 9, 671. [CrossRef]

14. Brown, T. Change by Design: How Design Thinking Transforms Organizations and Inspires Innovation; Harper Business: New York, NY, USA, 2009.

15. Martin, R.L. The Design of Business: Why Design Thinking Is the Next Competitive Advantage; Harvard Business School Press: Boston, MA, USA, 2009.

16. Nguyen, L.V.; Jung, J.J.; Hwang, M. OurPlaces: Cross-Cultural Crowdsourcing Platform for Location Recommendation Services. ISPRS Int. J. Geo-Inf. 2020, 9, 711. [CrossRef]

17. Prahalad, C.K.; Ramaswamy, V. Co-creation Experiences: The Next Practice in Value Creation. J. Interact. Mark. 2004, 18, 5-14. [CrossRef]

18. Elwood, S.; Leszczynski, A. Privacy reconsidered: New representations, data practices, and the geoweb. Geoforum 2011, 42, 6-15. [CrossRef]

19. Langley, P.; Leyshon, A. Platform capitalism: The intermediation and capitalisation of digital economic circulation. Financ. Soc. 2017, 3, 11-31. [CrossRef]

20. Pasquale, F. Two Narratives of Platform Capitalism. Yale L. Poly Rev. 2016, 35, 309. 
21. Jonietz, D.; Antonio, V.; See, L.; Zipf, A. Highlighting Current Trends in Volunteered Geographic Information. ISPRS Int. J. Geo-Inf. 2017, 6, 202. [CrossRef]

22. Gibson, W. Neuromancer; Harper-Collins: New York, NY, USA, 1984.

23. Batty, M.; Miller, H.J. Representing and visualizing physical, virtual and hybrid information spaces. In Information, Place, and Cyberspace; Janelle, D.G., Hodge, D.C., Eds.; Springer: London, UK, 2000; pp. 133-146.

24. Cairncross, F. The Death of Distance: How the Communications Revolution Will Change Our Lives; Harvard Business School Press: Harvard, MA, USA, 1997.

25. Couclelis, H. Editorial: The death of distance. Environ. Plan. B Plan. Des. 1996, 23, 387-389. [CrossRef]

26. Batty, M. Virtual geography. Futures 1997, 29, 337-352. [CrossRef]

27. Castells, M. The Internet Galaxy; Oxford University Press: Oxford, UK, 2002.

28. Dodge, M.; Kitchin, R. Atlas of Cyberspace; Addison-Wesley: London, UK, 2001.

29. Townsend, A. Network cities and the global structure of the internet. Am. Behav. Sci. 2001, 44, 1697-1716. [CrossRef]

30. Zook, M. The economic geography of commercial internet content production in the United States. Environ. Plan. A 2000, 32, 411-426. [CrossRef]

31. Brunn, S.; Dodge, M. Mapping the 'worlds' of the world wide web. Am. Behav. Sci. 2001, 44, 1717-1739. [CrossRef]

32. Zook, M. The geographies of the internet. Annu. Rev. Inf. Sci. Technol. 2006, 40, 53-78. [CrossRef]

33. Kitchin, R. Towards geographies of cyberspace. Prog. Hum. Geogr. 1998, 22, 385-406. [CrossRef]

34. Cohen, J.E. Cyberspace as/and space. Columbia Law Rev. 2007, 107, 210-256.

35. Juergens, C. Digital Data Literacy in an Economic World: Geo-Spatial Data Literacy Aspects. ISPRS Int. J. Geo-Inf. 2020, 9, 373. [CrossRef]

36. Jansena, B.J.; Spink, A.; Saracevi, T. Real life, real users, and real needs: A study and analysis of user queries on the web. Inf. Process. Manag. 2000, 36, 207-227. [CrossRef]

37. Wickham, H. Rvest Package Demonstration. 2015. Available online: https://github.com/hadley/rvest/blob/master/demo/ tripadvisor.R (accessed on 12 January 2019).

38. Barata-Salgueiro, T. Alojamentos Turísticos em Lisboa. Scr. Nova-Rev. Electrónica Geogr. Cienc. Soc. 2017, 21. [CrossRef]

39. Mendes, L. Gentrificação turística em Lisboa: Neoliberalismo, financeirização e urbanismo austeritário em tempos de pós-crise capitalista 2008-2009. Cad. Metrop. 2017, 19, 479-512. [CrossRef]

40. Malet-Calvo, D.; Ramos, M. Suddenly last summer: How the tourist tsunami hit Lisbon. Rev. Andal. Antropol. 2018, 15, 47-73. [CrossRef]

41. Cocola-Gant, A.; Gago, A. Airbnb, buy-to-let investment and tourism-driven displacement: A case study in Lisbon. Environ. Plan. A Econ. Space 2019, 53, 1671-1688. [CrossRef]

42. Sequera, J.; Nofre, J. Shaken, not stirred. City 2018, 22, 843-855. [CrossRef]

43. Brito-Henriques, E.; Paiva, D.; Costa, P. Cyborg urbanization beyond the human: The construction and ruination of the Matinha gasworks site. Urban Geogr. 2019, 40, 1596-1615. [CrossRef]

44. Malheiros, J.; Carvalho, R.; Mendes, L. Gentrification, residential ethnicization and the social production of fragmented space: Theory and evidence from two multi-ethnic neighbourhoods, in Lisbon and Bilbao. Finisterra-Rev. Port. Geogr. 2013, 48, 109-135. [CrossRef]

45. Paiva, D. Collapsed Rhythms: The Impact of Urban Change in the Everyday Life of Elders. Space Cult. 2016, 19, 345-360. [CrossRef]

46. Visconti, R. The Valuation of Digital Intangibles; Springer: London, UK, 2020. 